\title{
Detection of Portal Systemic Shunts by Hepatopulmonary Scanning Using $I^{131}$ MAA

\author{
Study and Application of Macroaggregated Albumin \\ (MAA) Lablled with I $^{131}$ (III)
}

\begin{abstract}
Hideo Ueda, M.D., Kenichi Krtani, M.D., Haruo Kameda, M.D., Hideo YAmada, M.D., and Masahiro Iro, M.D.
\end{abstract}

\begin{abstract}
Hepatopulmonary scintiscannings performed following the intrasplenic injection of I $^{131}$ MAA (macroaggregated albumin) were proved to be a useful method for the study of the portal circulation. Not only the accumulation of MAA in the liver and spleen, which was evidenced in control patients, lungs were also visualized in some patients with liver cirrhosis indicating the presence of portal systemic shunts. It was suggested that this technique was a more sensitive means to detect the presence of shunts than the roentgenologic study for esophageal varices and the previously reported methods using radioactive gas. Intrasplenic injection of radioactive rare gases was performed simlultaneously on the same patients not only to detect shunts but to measure human hepatic blood flow by the method previously reported by one of the authors. The $t \frac{1}{2}$ of the washout of the radioactivity from the liver, after intrasplenic injection of saline solution of $\mathrm{Kr}^{85}$ or $\mathrm{Xe}^{133}$, were all prolonged in patients with hepatitis and liver cirrhosis, compared with those in 3 patients having hemolytic anemia.
\end{abstract}

$\mathrm{T}$ HE abnormality of the portal circulation in patients with hepatic disease has been studied in various ways by many investigators. Esophageal varices can be shown by the esophagoscope ${ }^{1,2}{ }^{2)}$ and X-ray examination $^{31,4)}$ as a clear evidence of abnormal shunting of the portal circulation. Percutaneous splenoportography also provides us with more detailed information about the abnormal circulation of the portal system. ${ }^{51,6)}$ Recently, injection of radioactive isotopes, such as $\mathbf{I}^{131}$ lablled human serum albumin ${ }^{7)}$ or $\mathrm{Kr}^{85}$ solution, ${ }^{8)}$ into the spleen has been presented as a useful and convenient way to demonstrate portal systemic shunts.

The application of a new radioactive pharmaceutical, ${ }^{131}$ MAA, proTokyo.

From the Second Department of Internal Medicine, Faculty of Medicine, University of Tokyo,

This study was read before the 4th annual meeting of Japanese Society of Nuclear Medicine, Tokyo (Nov. 1964).

This study was partially supported by the International Atomic Energy Agency under research contract $270 / \mathrm{RB}$. 
Table I. Clinical and Laboratory

\begin{tabular}{|c|c|c|c|c|c|c|c|c|c|c|}
\hline \multirow[b]{2}{*}{ No. } & \multirow[b]{2}{*}{ Name } & \multirow[b]{2}{*}{ Sex } & \multirow[b]{2}{*}{ Age } & \multirow[b]{2}{*}{ Clinical Diagnosis } & \multicolumn{6}{|c|}{ Laboratory examination findings } \\
\hline & & & & & $\begin{array}{l}\text { Total } \\
\text { protein } \\
\text { Gm. } \%\end{array}$ & $\mathrm{~A} / \mathrm{G}$ & $\begin{array}{l}\text { Icterus } \\
\text { index }\end{array}$ & $\begin{array}{l}\text { BSP \% } \\
\text { (45 min.) }\end{array}$ & $\mathrm{ZnTT}$ & $\begin{array}{c}\text { Total } \\
\text { cholesterol } \\
\text { in serum } \\
\text { Gm. } \%\end{array}$ \\
\hline 1 & T.S. & $\mathbf{M}$ & 17 & hemolytic anemia & 7.2 & 1.7 & 45 & 7.5 & 8 & 165 \\
\hline 2 & S.K. & $\mathbf{M}$ & 20 & hemolytic anemia & 8.2 & 1.3 & 21 & 5.0 & 8 & 85 \\
\hline 3 & Y.S. & $\mathbf{M}$ & 32 & hemolytic anemia & 7.8 & 1.2 & 18 & 2.5 & 12 & 132 \\
\hline 4 & T.S. & $\mathbf{M}$ & 17 & $\begin{array}{l}\text { hemolytic anemia } \\
\text { acute hepatitis }\end{array}$ & 7.6 & 1.5 & 175 & 12.5 & 11 & 185 \\
\hline 5 & T.K. & $\mathbf{F}$ & 58 & $\begin{array}{l}\text { chronic hepatitis } \\
\text { cholelithiasis }\end{array}$ & 7.0 & 1.7 & 45 & 7.5 & 8 & 160 \\
\hline 6 & T.Y. & F & 28 & $\begin{array}{l}\text { biliary cirrhosis } \\
\text { congenital syphilis }\end{array}$ & 7.3 & 0.6 & 105 & 15.0 & 28 & 322 \\
\hline 7 & W.K. & M & 42 & liver cirrhosis & 8.8 & 0.3 & 10 & 12.5 & 23 & 140 \\
\hline 8 & Y.M. & $\mathbf{M}$ & 47 & $\begin{array}{l}\text { liver cirrhosis } \\
\text { hypertension }\end{array}$ & 8.2 & 0.9 & 5 & 12.5 & 9 & 235 \\
\hline 9 & S.M. & $\mathbf{M}$ & 55 & $\begin{array}{l}\text { liver cirrhosis } \\
\text { hypertension }\end{array}$ & 8.3 & 0.7 & 5 & 7.5 & 19 & 200 \\
\hline
\end{tabular}

duced first by Dr. Taplin") and manufactured further adequately by us ${ }^{10) *}$ provided another helpful technique to detect portal systemic shunts, by measuring hepatopulmonary distribution of MAA with a scintiscanning after intrasplenic injection of $\mathrm{I}^{131} \mathrm{MAA}$. The principle of this method is as follows: Since adequately prepared MAA is completly trapped by the capillary net work where it is first delivered, ${ }^{10}$ MAA can not reach the post capillary blood stream unless there is a by-pass route whose diameter is large enough to permit the passing of MAA; therefore, MAA injected in the spleen is trapped in the hepatic capillary net in a normal subject and thus can appear in the pulmonary system only under the presence of portal systemic shunts. In such cases the amount of MAA trapped by the lung can be used as an indication of the degree of the shunt flow.

In order to evaluate the reliability and sensitivity of this method, intrasplenic injection of radioactive rare gas saline solution such as $\mathrm{Kr}^{85}$ or $\mathrm{Xe}^{133 * *}$ with expiratory air monitoring and $\mathrm{X}$-ray examination of esophageal varices, were performed on the same patients. In addition, hepatic blood flow

* Through Daiichi-Pure Chemical Co., Tokyo, Japan.

** Through ORNL. 
Data on Patients Examined

\begin{tabular}{|c|c|c|c|c|}
\hline $\begin{array}{c}\text { Liver } \\
\text { (finger breadth) }\end{array}$ & $\begin{array}{c}\text { Spleen } \\
\text { (finger breadth) }\end{array}$ & $\begin{array}{l}\text { X-ray study } \\
\text { of varices }\end{array}$ & Liver biopsy findings & Laparoscopy findings \\
\hline 1 & 6 & $(-)$ & not carried out & not carried out \\
\hline 0 & 4 & $(-)$ & not carried out & not carried out \\
\hline 2.5 & 3 & $(-)$ & not carried out & not carried out \\
\hline 2 & $4-5$ & $(-)$ & acute hepatitis & $\begin{array}{l}\text { acute hepatitis } \\
\text { with splenomegaly }\end{array}$ \\
\hline 0 & 0 & $(-)$ & $\begin{array}{l}\text { chronic hepatitis } \\
\text { (moderate) }\end{array}$ & $\begin{array}{l}\text { almost normal liver } \\
\text { pericholecystitis }\end{array}$ \\
\hline $2-3$ & 4 & $(+)$ & biliary cirrhosis & biliary cirrhosis \\
\hline 0 & 2 & $(-)$ & liver cirrhosis & liver cirrhosis \\
\hline $3-4$ & 0.5 & $(-)$ & liver cirrhosis & liver cirrhosis \\
\hline 0 & 0 & $(+)$ & liver cirrhosis & $\begin{array}{l}\text { liver cirrhosis } \\
\text { with ascites }\end{array}$ \\
\hline
\end{tabular}

measurements were accomplished by the external monitoring of hepatic clearance of radioactive gas after the intrasplenic injection of the solution.

\section{Materials and Methods}

The clinical and laboratory data of 9 patients studied are summarized in Table I. Three hemolytic anemias were used as control subjects for this study. Case No. 1 and No. 4 is the same patient examined on different dates who later had symptoms of hepatitis 2 months following blood transfusion in the preparation for the splenectomy. All patients studied were kept fasting 8 hours, or more before study.

Previous to scintigram study by MAA, 0.5 to $1.5 \mathrm{ml}$. of $\mathrm{Kr}^{85}$ saline solution, was injected into the spleen and the washout curve of the radioactivity over the liver was recored externally by the pen recorder through a ratemeter operating with a 1.0 sec. time constant. At the time of this procedure a Geiger Müller Counter was placed over the mouth of the patient so that the appearance of radioactivity in the expiratory air could be detected. In the 3 patients No. 7, No. 8, No. $9 \mathrm{Xe}^{133}$ solution was mixed with $\mathrm{Kr}^{85}$ solution before injection, in order to obtain washout curves of both gases by double isotope technique. Washout curves were replotted on the semi-log paper to obtain the exponential decrease of radioactivity from the liver. The disapperance rate constant $(k)$ was calculted by $k=\frac{\log 2}{t^{\frac{1}{2}}}$. Hepatic blood flow (HBF) was calculted by the equation below. ${ }^{11)-13)}$ 


$$
\mathrm{HBF}=\frac{k \lambda 100}{\rho}(\mathrm{ml} . \text { per } 100 \mathrm{Gm} \text {. of liver weight per min. })
$$

$\lambda$ indicates the partition coefficient of $\mathrm{Kr}$ or Xe between liver and blood. As we have no reliable data about $\lambda$, we assumed it as a unity, although in reality, it is considered to vary in certain range from case to case. $\rho$ is the specific gravity of the liver and was assumed as 1.05. The appearance time of radioactive gas into the expiratory air was compared with the peak time over the liver. If the former is faster than the latter, this can be a good indication of the presence of abnormal flow which by-passes the hepatic vascular bed.

Following this study, 200 to $300 \mu \mathrm{c}$ of $\mathrm{I}^{131} \mathrm{MAA}$ in a volume of $1.0 \mathrm{ml}$. or

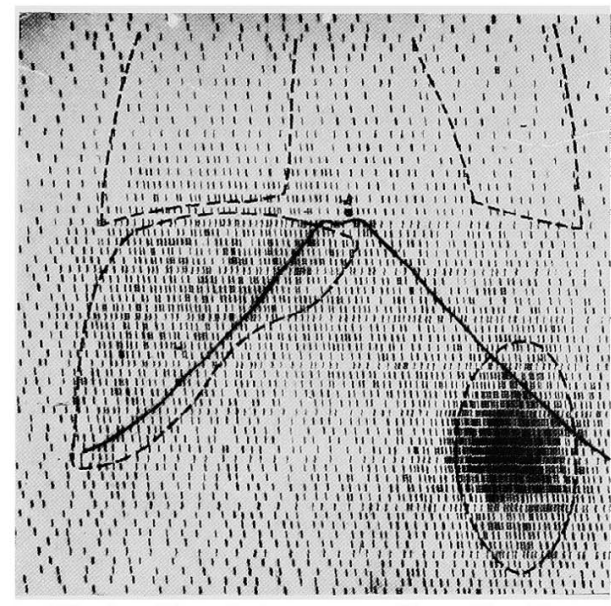

Fig. 1. Hemolytic anema (Case No. 1).

$I^{131}$ MAA injected into the spleen was trapped exclusively in the spleen and the liver. No pulmonary scintigram can be visualized in this case indicating the absence of portal systemic shunts.

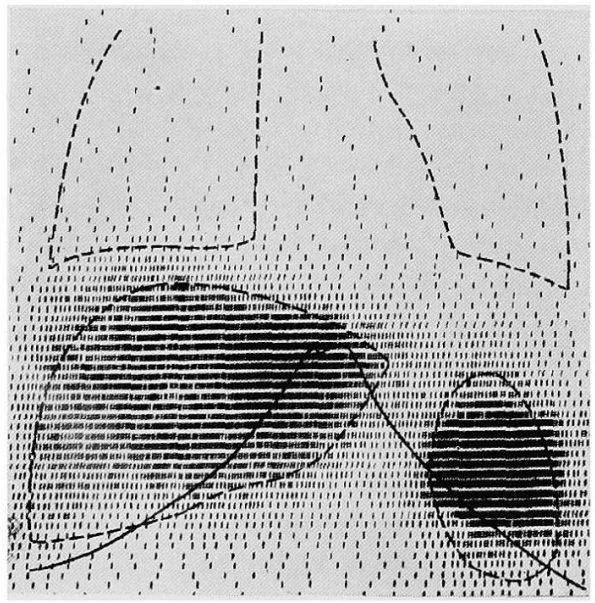

Fig. 2. Liver cirrhosis (Case No. 8).

Absence of pulmonary scintigram is the evidence of the absence of significant portal systemic shunts. No varices can be detected by the repeated roentgenologic study in this case. 


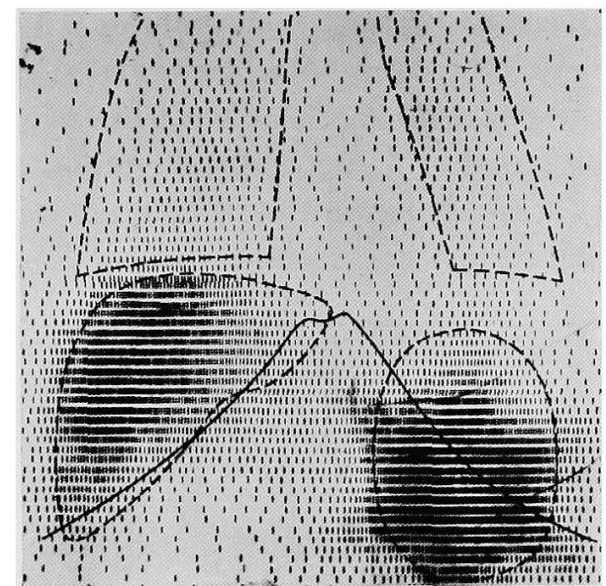

Fig. 3. (Case No. 7). Liver cirrhosis.

Clear contour of lungs indicates the presence of moderate portal systemic shunts. No varices can be shown by the routine roentgenologic examination (See Fig. 8).

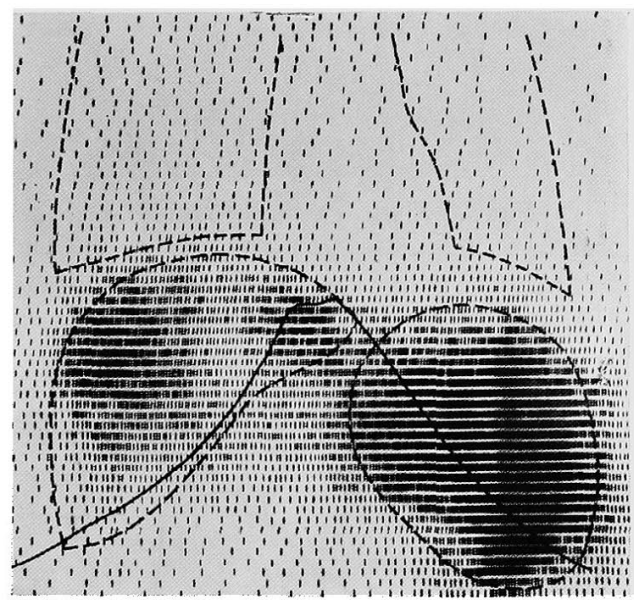

Fig. 4. Liver cirrhosis (Case No. 9).

Pulmonary scintigram of moderate degree visualized in this case indicates the by-pass flow is not so great as in case No. 6, although marked esophageal varices can be shown by roentgenologic examination (Fig. 8).

less was injected into the spleen percutaneously. Scintiscanning covering liver, spleen and lungs was performed immediately after injection. Scintiscanner used in this study was Shimazu SCC-30* $\left(3^{\prime \prime} \phi \times 2^{\prime \prime}\right.$ crystal) with 37 hole focusing collimator. The accumulation of MAA in the lung, compared with that in the liver, was used as an aid to estimate the grade of portal systemic shunts.

\section{Results}

Hepatopulmonary scintiscanning: Representative scintigrams are shown

* Through Shimazu Co., Kyoto, Japan. 
in Fig. 1 to Fig. 5. In contrast to Fig. 1 (control case), which shows accumulation of MAA exclusively in the liver and spleen, Fig. 3-Fig. 5 (cases with liver cirrhosis) show pulmonary accumulation of MAA in various degrees, indicating the presence of portal systemic shunts. Among these, one can see the most significant case in Fig. 5, which shows almost no accumulation of MAA in the liver, in contrast to the remarkable accumulation in lungs. One case of liver

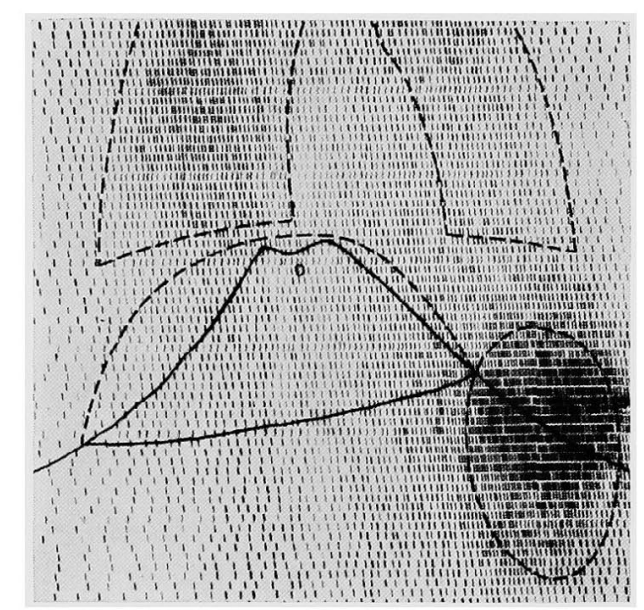

Fig. 5. Biliary cirrhosis (Case No. 6).

Marked contour of lungs suggests that a large amount of portal flow is directly introduced into the pulmonary system by-passing hepatic vascular bed. Note the absence of clear scintigram of the liver. The esophageal varices observed in this case is of moderate degree (Fig. 8).

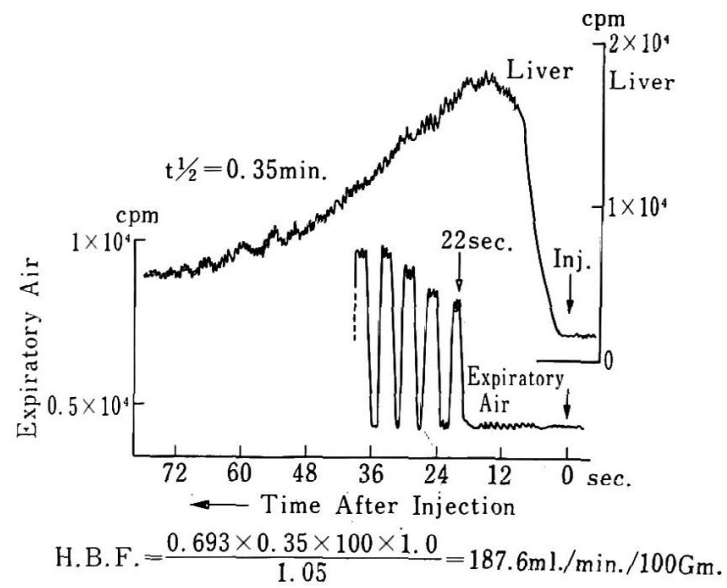

Fig. 6. Hemolytic anemia (Case No. 3).

Washout curve and appearance of $\mathrm{Kr}^{85}$ solution injected into the spleen. Washout curve can bc replotted in a semi-log paper single-exponentially. Appearance of radioactivity in the expiratory air was recorded $22 \mathrm{sec}$. after injection suggesting the absence of portal systemic shunts. 
Table II. Results of Rare Gas and MAA Study

\begin{tabular}{|c|c|c|c|c|c|c|c|}
\hline \multirow[b]{2}{*}{ No. } & \multirow[b]{2}{*}{ Name } & \multirow[b]{2}{*}{$\begin{array}{l}\frac{1}{2} \mathrm{~K}: \\
\text { min. }\end{array}$} & \multirow[b]{2}{*}{$\begin{array}{l}t \frac{1}{2} x_{e} \\
\text { min. }\end{array}$} & \multirow[b]{2}{*}{$\mathrm{t}_{\mathrm{2}} \mathrm{Kr} / \mathrm{t}^{\frac{1}{2} \mathrm{Xe}}$} & \multicolumn{2}{|c|}{ portal systemic shuts } & \multirow{2}{*}{$\begin{array}{c}\mathrm{HBF} \\
\mathrm{ml} . / 100 \\
\mathrm{Gm} . / \mathrm{min} .\end{array}$} \\
\hline & & & & & $\begin{array}{c}\text { gas method } \\
\text { (appearance time } \\
\text { intoexpiratory air) }\end{array}$ & scan method & \\
\hline 1 & T.S. & 0.37 & & & $\left.\begin{array}{c}(-) \\
(22 \mathrm{sec} .\end{array}\right)$ & $(-)$ & 180.0 \\
\hline 2 & S.K. & 0.36 & & & $\begin{array}{c}(-) \\
(18 \text { sec. })\end{array}$ & $(-)$ & 184.0 \\
\hline 3 & Y.S. & 0.35 & & & $\left(\begin{array}{c}(-) \\
(15 \text { sec. })\end{array}\right.$ & $(-)$ & 187.6 \\
\hline 4 & T.S. & 0.76 & & & $\begin{array}{c}(-) \\
(15 \sec .)\end{array}$ & $(-)$ & 86.6 \\
\hline 5 & T.K. & 0.45 & & & $\left(\begin{array}{c}(-) \\
(12 \mathrm{sec} .\end{array}\right)$ & $(-)$ & 144.6 \\
\hline 6 & T.Y. & 0.67 & & & $\begin{array}{l}(+) \\
(2 \text { sec. })\end{array}$ & $(+t)$ & 98.4 \\
\hline \multirow{2}{*}{7} & W.K. & 0.88 & 0.96 & 0.96 & $\begin{array}{c}( \pm)^{*} \\
(3 \mathrm{sec} .)\end{array}$ & \multirow{2}{*}{$(+)$} & 75.0 \\
\hline & $"$ & 0.63 & 0.67 & 0.93 & $\begin{array}{l}( \pm)^{*} \\
(2 \mathrm{sec} .)\end{array}$ & & 98.0 \\
\hline 8 & Y.N. & 0.71 & 0.84 & 0.845 & $\begin{array}{c}(-) \\
(13 \text { sec. })\end{array}$ & $(-)$ & 93.0 \\
\hline \multirow{2}{*}{9} & J.M. & 0.98 & 0.73 & 1.34 & $\begin{array}{l}(+) \\
(3 \sec .)\end{array}$ & \multirow{2}{*}{$(+)$} & 67.3 \\
\hline & " & 0.89 & 0.63 & 1.39 & $\begin{array}{c}(+) \\
(2-3 \text { sec. })\end{array}$ & & 74.2 \\
\hline
\end{tabular}

* Radioactivity appearing in early phase was not enough to be differentiated from the background radioactivity.

cirrhosis (Fig. 2) shows no contour of lungs. This is thought to be the evidence of the absence of functioning shunts through spleno-portal system in this case. Two other cases with liver cirrhosis (Fig. 3, Fig. 4) show pulmonary accumulation of MAA, in moderate degree, which indicates the by-pass flow of these cases are less than that of case No. 6 (Fig. 5).

Rare gas study: Results of rare gas study are summarized in Table II, According to the results of Long et al.,8) the early appearance of radioactivity in the expiratory air means the presence of portal systemic shunts. No. 6 and No. 9 indicate the definite presence of shunts and these findings are compatible with the observation of the MAA scintigram study. In No. 7, the early appearance of radioactive rare gas into the expiratory air was not significant enough to confirm the presence of shunts.

Hepatic blood flow estimated simultaneously by the clearance of radio- 


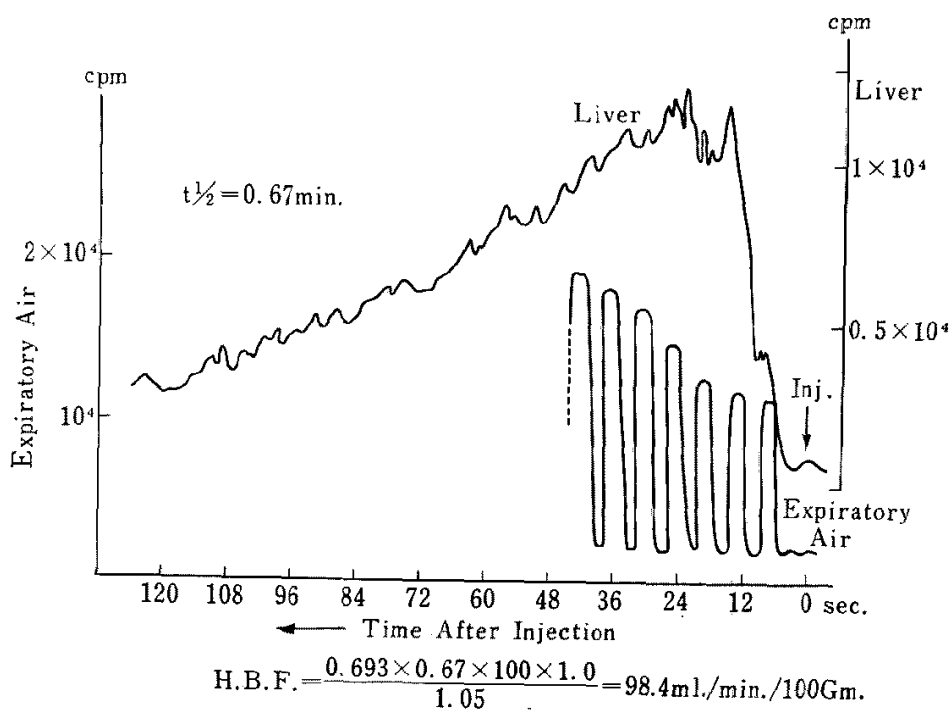

Fig 7. Biliary cirrhosis (Case No. 6).

Washout curve from the liver was also single exponential. Abnormally early appearance of the radioactivity in the expiratory air was recorded suggesting the presence of shunts.

activity from the liver is indicated also in Table II. The average value of hepatic blood flow in 3 control cases is $184 \pm 3.6 \mathrm{ml} . / 100 \mathrm{Gm}$. $/ \mathrm{min}$., whereas cases with liver cirrhosis showed significantly decreased blood flow ranging from 67 to $98 \mathrm{ml} / 100 \mathrm{Gm}$. $/ \mathrm{min}$. Actual recordings of radioactive rare gas washout curve from the liver and the appearance of radioactivity in the expiratory air are shown in Fig. 6 and in Fig. 7 ; Fig. 6 (case No. 3) shows the rapid clearance of radioactivity with delayed appearance in the expiratory air. Fig. 7 (case No. 6) shows the delayed clearance from the liver accompanied by the abnormally early appearance of radioactivity in the expiratory air.

\section{Discussion}

Recent development of a new radiopharmaceutical ${ }^{131}$ labelled macroaggregated albumin by Taplin ${ }^{91}$ et al., Wagner et al., ${ }^{14)}$ and our group ${ }^{10)}$ in this country has stimulated us to use this material for the study of portal circulation in man.

Because of the carefully prepared particle size of MAA used in this study, ${ }^{10}$ once MAA is introduced into the blood stream, it is almost completely trapped in the capillary net where it is first delivered. Accordingly, when MAA is injected into the splenic pulp of the cases with normal portal circulation, it is carried away to the liver via splenic vein and completely trapped by the capillary of hepatic sinusoid. And it permits the visualization of the 
liver by scintiscanning, although the capture of some amounts of MAA in the spleen is also observed. If the portal system is intact, there can be no way for the MAA to reach the pulmonary capillary. Actually control cases in this study showed no accumulation of MAA in the lung (Case No. 1, No. 2, No. 3 ). When the lung is visualized by this procedure, it can be explained only by the presence of shunts in the portal circulation, "portal systemic shunts."

Careful observation of the liver scintigram in this study also shows nonhomologous distribution of MAA in the liver. The nonhomogeneity of MAA distribution in the liver is most demonstrable in Fig. 4 which shows marked accumulation of the MAA in the right and left parts and decreased accumulation in the middle. One possible explanation for this phenomenon can be made via the stream line blood flow of the portal system into the liver (A detailed study of this phenomenon is to be reported shortly).

Roentgenologic examination and esophagoscope for the detection of esophageal varices have been used most commonly for the study of portal circulation. ${ }^{1-4)}$ However it is also a well known fact that the absence of varices by such methods does not always mean the absence of portal systemic shunts. ${ }^{21,}{ }^{6}$ ) Percutaneous splenoportography informs us of much more details concerning portal circulation.5),6) Although this is a very refined way for studying portal circulation, it requires a skillful team in the procedure and sometimes can produce uncomfortable side effects.

Recently Long and co-workers ${ }^{8)}$ proposed a new means for the evaluation of abnormal portal circulation using $\mathrm{Kr}^{85}$ solution based on animal experiments. By a similar technique, Sherlock et al. ${ }^{15)}$ showed the presence of portal pulmonary shunts through the intrasplenic injection of $\mathrm{Kr}^{85}$ solution, followed by the continuous sampling of arterial blood.

In order to evaluate the advantage and the limitation of our new technique, each case was carefully examined, by various procedures as mentioned above. Example; such as in case No. 6, the density of pulmonary scanning is significantly higher than that of hepatic scanning (Fig. 5), indicating that a large amount of MAA injected into the spleen reached directly the pulmonary capillaries by-passing the hepatic capillaries. In the $\mathrm{Kr}^{85}$ study, the higher radioactivity was able to be detected in the expiratory air in the early stage before hepatic peak had appeared (Fig. 7). Roentgenologic examination rcvealed, however, esophgeal varices in this case is of moderate degree compared with those in case No. 9 (Fig. 8). This result indicates that some route other than esophageal varices played the major role in the by-pass flow in this case. In case No. 9 in which esophageal varices can be demonstrated more markedly than in No. 6 (Fig. 8), the density of pulmonary scanning relative to that of the liver is lower than in No. 6 , suggesting that the by-pass flow of No. 9 should be 


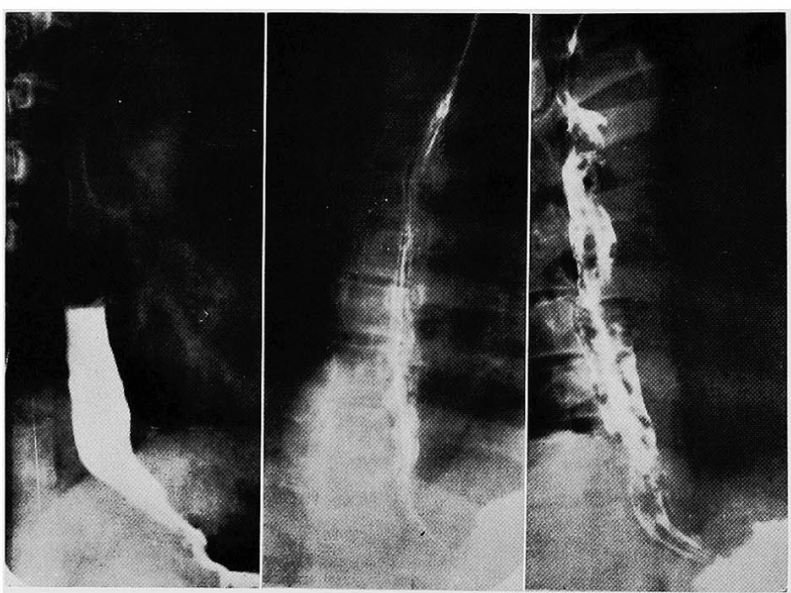

Fig. 8. Esophageal findings by $\mathrm{X}$-ray study in three different patients with liver cirrhosis. Case No. 7 (left) Case No. 6 (middle) Case No. 8 (right).

Note the discrepancy of results of roentgenologic examination and MAA study.

less than that of No. 6. In case No. 7, although the density of lung is lower than that of the liver, the clearly observed pulmonary contour strongly suggests the presence of shunts. However the results of $\mathrm{Kr}^{85}$ study does not confirm the presence of shunts. Besides, esophgeal varices could not be shown by repeated X-ray study (Fig. 8). This discrepancy of the results encouraged us to continue further the study by MAA. In the present stage, results of scanning seem to be more sensitive and reliable to detect shunts than other methods performed before. In our method, measurement can be performed in a more stable period by spending sufficient time even for changing the sensitivity of the detector, since MAA in the lung can remain there during the entire period of observation.

The detection of minor portal systemic shunts in early stage of cirrhosis, as in case No. 7, may not seem to have so much clinical significance as in a case of late-stage cirrhosis; because the collateral veins in early stage have less danger of rupturing or bleeding and they thus produce less severe problems ordinarily encountered. If shunts of slight degree can be detected easily by this scanning method, it may add new interesting information to the study of portal hemodynamics not only in case of cirrhosis, but in some other diseases ${ }^{17)-19)}$ with various degree of shunts. It is still unknown to us whether MAA can pass the intra-hepatic shunts* which are reported to be not uncommonly present in cirrhotic patients. ${ }^{20-21)}$ This problem will be investigated further in cases having various hepatic disorders, as discussed above.

\footnotetext{
* See addendum.
} 
So far our experience of the MAA method is still too small in number to draw any definite conclusion as to the merit of this new method. The volume of injection is less than $1.0 \mathrm{ml}$., it can be easily performed in the laboratory equipped only with an ordinary scintiscanner, without collaboration of a trained team such as in case of splenoportography. The radiation to the patient is quite limited and within the safety limit, ${ }^{10}$ all because of the rapid metabolism and clearance of such material both from lung and liver. Toxicity study of this material ${ }^{10}$ ) has also revealed that this material has neither antigenicity to men nor mechanical effect on the hemodynamics via the dose given to a patient. ${ }^{14)}$ Authors are further evaluating this method as a routine means for the study of portal circulation.

Besides the detection of portal systemic shunts, we have applied this radioactive rare gas method to the measurement of human hepatic blood flow for the first time, based upon the previous report on a dog performed by one of collaborators. ${ }^{11)}$ As is stated in the dog study ${ }^{11)}$ the increased amount of lipid in the liver accompanied with the increased partition of radioactive rare gas, between liver and blood, led us to observe the slower clearance of such gases from the liver. At present we have no direct or definite means to measure this partition coefficient of such gas between liver and blood, we have simply assumed it as a unity and calculated the values of hepatic blood flow such as in Table II; therefore, strictly speaking, one can not compare these values with each other. As lipid content in the liver was reported to be almost constant in normal fasting man, $\left.{ }^{22)},{ }^{23}\right)$ in the 3 cases with hemolytic anemia where liver damage is thought to be at a minimum, the observed blood flow could be compared with one another. These values are rather higher than those previously reported by other methods used on normal subjects. ${ }^{24}$ We consider that there is an overestimation of blood flow by our method, probably because of the assumption that $\lambda$ is 1.0. In other cases with liver damage simple comparison of blood flow value can not be justified without accurate evaluation of $\lambda$. The lipid content of liver tissue in such patients can vary to a great degree (from 3 or $5 \%$ of normal value up to more than $30 \%$ in severe fatty liver). ${ }^{25)}$, 26) Moreover lipid content in the blood is known to increase especially in obstructive jaundice and biliary cirrhosis. ${ }^{27)}$ The increase of lipid content in liver increases the partition coefficient of $\mathrm{Kr}$ or $\mathrm{Xe}$, whereas the increase of lipid in the blood decreases this value; And the change of partition coefficient of $\mathrm{Xe}(\lambda(\mathrm{Xe}))$ is more strongly influenced by the lipid content of liver and blood than that of $\operatorname{Kr}(\lambda(\mathrm{Kr}))$, because of the higher lipid solubility of $\mathrm{Xe}$ gas. Therefore, the ratio of partition coefficient of both gases in a same subject $\frac{\lambda(\mathrm{Kr})}{\lambda(\mathrm{Xe})}$ can also be varied according to the degree of lipid 
content in the liver and blood. Good examples of this mechanism were reported through the results of a double isotope study. ${ }^{11)}$ The ratio of coefficient $\frac{\lambda(\mathrm{Kr})}{\lambda(\mathrm{Xe})}$ of each case examined is expressed here by the ratio of clearance rate of both gases $\frac{t \frac{1}{2} \mathrm{Kr}}{t \frac{1}{2} \mathrm{Xe}}$. We may presume the change of partition coefficient in each case from the change of the ratio of partition of 2 gases when measured by double isotope study. At present, hepatic blood flow measurement, using radioactive rare gas solution, has certain difficulties in clinical uses as routine procedure. In spite of these difficulties, however, this technique has some advantages as follows; the material is a single element and is not subject to the variability of radiopharmaceuticals at each shipment. Radiation to the patient is minimized by the rapid clearance through lung; also the time required for the procedure is only a few minutes. We can expect a great potential in this method if the partition coefficient problem can be solved by using double isotope technique as herein described. Recently, Rees ${ }^{28)}$ et al. reported in his dog experiments that the blood flow, obtained by the portal injection of rare gas, can not indicate the total hepatic blood flow because the portal vein and arterial stream is functionally separated in the dog. We are currently working on this problem.

\section{SUMMARY}

After splenic injection of $\mathrm{I}^{131}$ MAA, its distribution in the liver and lungs was studied by scintiscanning method. Appearance of pulmonary scanning indicates the presence of portal systemic shunts. Three cases with hemolytic anemia, 2 cases having hepatitis and 1 with liver cirrhosis showed no accumulation of this material in the lungs. Among 4 cases with liver cirrhosis portal systemic shunts were revealed in 3 by this method. This method was evaluated in contrast with conventional methods such as roentgenologic study of esophageal varices and radioactive rare gas method, and the sensitiveness and usefulness of this new technique was thus suggested.

Hepatic blood flow was measured in 9 patients using radioactive rare gas clearance from the liver. Average blood flow of 3 hemolytic anemias was calculated as $184 \pm 3.6 \mathrm{ml} . / 100 \mathrm{Gm}$. min. by this method. Blood flow values in 2 heptitics and 4 cirrhotics were all markedly reduced compared with those of hemolytic anemias.

\section{Addendum}

After preparation of our original manuscript we have been able to confirm 
2 cirrhotic cases with significant portal systemic shunt showing marked accumulation of MAA in both lungs as was observed in case No. 6.

In the above manuscript we did not make it clear whether delivery of MAA into lung occurred either through intra-hepatic shunt or extra-hepatic shunt. By placing the detector over the liver and recording initial accumulation curve of $I^{121}$ MAA into the liver, it is now possible to conclude the large portion of the observed shunt flow by such a technique is due to intra-hepatic shunt. This is indicated by a big "hump", whereas in normal cases accumulation curves end to a plateau. Detail of this study is to be reported shortly. ${ }^{291}$

We wish to express our thanks to the collaboration of Drs. T. Iwase and S. Kaihara.

\section{REFERENCES}

1. Jackson, C., Tucker, G., Clere, L.H., Lukens, R.M., and Moore, W.F. : J.A.M.A. 85 : 870, 1925.

2. Palmer, E.D. and Brick, I.B. : Am. J. Med. Sci. 227 : 149, 1954.

3. Schazki, R.: Arch. Surg. 41 : 1084, 1940.

4. Kirsh, I.E., Blakemore, C. C., and Bennett, H.D. : Am. J. Röntgenol. 74 : 477, 1955.

5. Dreyer, B. and Butz-Olsen, O.E. : Lancet, 530, 1952.

6. Atkinson, H., Barnett, E., Shcrlock, S., and Steiner, R.E. : Quart, J. Med. 24: 77, 1955.

7. Greenlow, R.H. and Schwartz, S.I. : J. Nucl. Med. $2: 85,1961$.

8. Long, R.L., Lombardo, C. R, and Braunwald, E.: Ann. Surg. 151 : 146, 1960.

9. Taplin, G.V., Johnson, D.E., Dore, E.K., and Kaplan, H.S.: J. Nucl. Med. 5 : 259, 1964.

10. Ogawa, H., Nitta, K., Ueda, H., Kaihara, S., and Iio, M. : Jap. Heart J. to be published.

11. Iio, M., Wagner, H.N., Ross, R.S., Ueda, K., Lichtlen, P., Jude, J.R., Knickerbocker, C., and Burne, H.R.: J. Nucl. Med. 4: 213, 1963.

12. Kety, S.S. and Schmidt, C.F.: Am. J. Physiol. 143 : 53, 1945.

13. Herd, J.A., Hollenberg, M., Thorburn, G.D., Kopald, H.H., and Barger, A. C. : Am. J. Physiol. 203 : 122, 1962.

14. Wagner, H.N., Sabiston, C.D., Iio, M., and McAfee, J.G. : J.A.M.A. $187: 601,1964$.

15. Shaldon, S., Caesen, J., Chiandussi, L., Williams, H.S., Sheville, E., and Sherlock. S.: New Eng. J. Med. $265: 410,1961$.

16. Palmer, E.D. and Brick, I.B.: Am. J. Med. $17: 641,1954$.

17. MacDonald, R.A. : Arch. Int. Med. 99 : 266, 1956.

18. Carcia-Palmieri, M.R. and Marcial-Roja, R.A. : Am. J. Med. 27 : 811, 1959.

19. MacIndoe, A.H.: Arch. Path. 5: 23. 1928.

20. Popper, H., Elias, H., and Petty, D.E. : Am. J. Clin. Path. 22 : 717, 1952.

21. Hales, M.R., Allen, J.S., and Hall, E.M. : Am. J. Path. 35 : 909, 1959.

22. Thesis, E.R. : J. Biol. Chem. 82 : 327. 1929.

23. Harris, T. A. B. : Mode of Action of Anesthetics, William \& Wilkins Go., Baltimore, p. 168, 1951.

24. Bradley, S.E., Ingelfinger, F.J., and Bradlay, G.P.: Circulation. 5 : 419, 1952.

25. Ralli, E.P., Rubin, S.H., and Rinzler, S. : J. Clin. Invest. 20 : 93, 413, 1941.

26. Stueck, G.H., Rubin, S.H., Clarke, D.H., Graef, I., and Ralli, E.P. : Am. J. Med. 5 ; 188.1948.

27. Thanhauser, S.J. : New Eng. J. Med. 237: 515, 546, 1947.

28. Rees, J. R., Redding, V. J., and Ashifield, R. : Lancet. 562, 1964.

29. Ueda, H., Kitani, K., Kameda, H., Yamada, H., and Iio, M. : Jap. Heart J. to be published. 